\title{
Development of Bedroom Module for Smart Variable Space Kazuyoshi Wada ${ }^{* 1}$, Toshihiko Suzuki ${ }^{* 2}$, Keisuke Takayama ${ }^{* 1}$, and Eiji Kubo ${ }^{* 1}$ \\ *1 Graduate School of System Design, Tokyo Metropolitan University 6-6 Asahigaoka, Hino, Tokyo 191-0065, Japan \\ *2 Faculty of Engineering, Kogakuin University
}

\begin{abstract}
:
The methods which improve space usage efficiency is important especially for city lives. Development of high-rise buildings and underground are one of the methods. However, those developments just lay out the spaces which are expanded in plane into vertical. Therefore, there are the physical and monetary limitations. Instead of stacking of single function spaces, the spaces which can change its functions easily/automatically depending on the situations are necessary. In this paper, we proposed smart variable space which realizes various functional spaces by changing its modules dynamically, and developed a bedroom module as an example of the module, and then, its basic functions were experimentally confirmed by test operation.
\end{abstract}

\section{INTRODUCTION}

Japan is going into depopulating society, now. The peak of Japan's population was 128 million in 2005, and then will decrease to less than 100 million in 2046 [1]. Social system which is based on population increasing has reached a turning point, and reduction and efficiency of the social system are necessary to adapt to the depopulating society.

Recently, the concept of compact city is noticed especially in local cities. Automobile society expanded commercial facilities and houses to suburbs. On the other hand, compact city aims to return those into the center of city [2]. The following merits are expected:

1). Merit of inhibition of using cars and promotion of using public transportation (reduction of $\mathrm{CO}_{2}$, decreasing of air pollution and noise, etc.)

2). Merit of inhibition of extensional development to suburbs (protection of natural environment, and promotion of efficiency of public investment)

3). Merit of high-degree application of urban area (people can reach every urban function by walk, saving of energy, etc.)

On the other hand, big cities like Tokyo have been attracting many people because of its high efficiency. The trend is no changes, and population inflow into the big cities is continuing. From the view points of coming depopulating society and saving the earth environment, more efficiency of the cities are demanded.

Cities, where various functions are concentrated in limited area, have been suffering from chronic space shortage. Therefore, high-rise buildings and underground have been developed to increase space usage efficiency. However, those developments just lay out the spaces which are expanded in plane into vertical; there are the physical and monetary limitations, obviously. Therefore, instead of stacking of single function spaces, the spaces which can change its functions easily/automatically depending on the situations are necessary to increase space usage efficiency.

In this paper, we propose smart variable space which realizes various functional spaces by changing its modules dynamically, and develop a bedroom module as an example of the module. Section 2 explains related researches, section 3 explains smart variable space and section 4 describes a proto type bedroom module for the space. Finally, section 5 offers conclusions.

\section{RELATED RESEARCH}

\subsection{Skeleton Infill}

Recently, a concept of a method called skeleton-infill to extend building duration has received attention. This is the method to enhance architectural sustainability by dividing a building into two factors: the skeleton (an empty space without partitions and equipment) and infill (changeable equipment and partitions). Building duration is generally decided not on physical duration of structural skeleton but on when it cannot respond to its residents' changes of family structure or life style. In fact, duration of an architecture would be longer if it can be adaptable such changes. The concept of the skeleton-infill which enables equipment having shorter duration than a building to be more renewable and inner room arrangement to be more changeable to respond to changes in lives has been widely accepted from the above point of view. However, infill which can change room arrangement is not easy to carry out and does not usually provide for enough changeability to respond to daily alternation of application thereof. Upon such problem consciousness, some case examples trying to solve those problems with "furniture combining architectural functions" which is like an intermediate between furniture and partitions or equipment have been carried out in order to deliver interior design of higher changeability [3]-[6].

\subsection{Architectural furniture}

In the above-mentioned, Infill is not provided with quick-response changeability against everyday application alteration, since it is supposed to be altered in a time-span of around 15 to 30 years. Reflecting such situation, "furniture combining architectural functions" to play an intermediate role between infill and furniture has appeared.

For example, Baumhaus, Nobuaki Furuya and Studio NASCA proposed a mechanism, as a trial to enhance 
sustainability of rented apartments which are expected to respond to various life styles, wherein architectural part is to be an empty space without partition like a skeleton, and interior provides furniture functioning as partition as well as closet which residents can arrange interior layout by deciding how the furniture is placed [3].

Suzuki named such the concept like an intermediate between infill and furniture as "furniture combining architectural functions - Architectural Furniture". Further, Architectural Furniture is defined as "what is able to segment space, provide functions in place, and to be moved and altered easily" [5][6].

Fig. 1 shows position of architectural furniture in interior environment. In the conventional interpretation, architecture means building, room arrangement and equipment, and furniture means big furniture and small furniture. From the perspective of the skeleton-infill, building is to be the skeleton, and room arrangement and equipment are to be the infill. The other elements are regarded as interior.

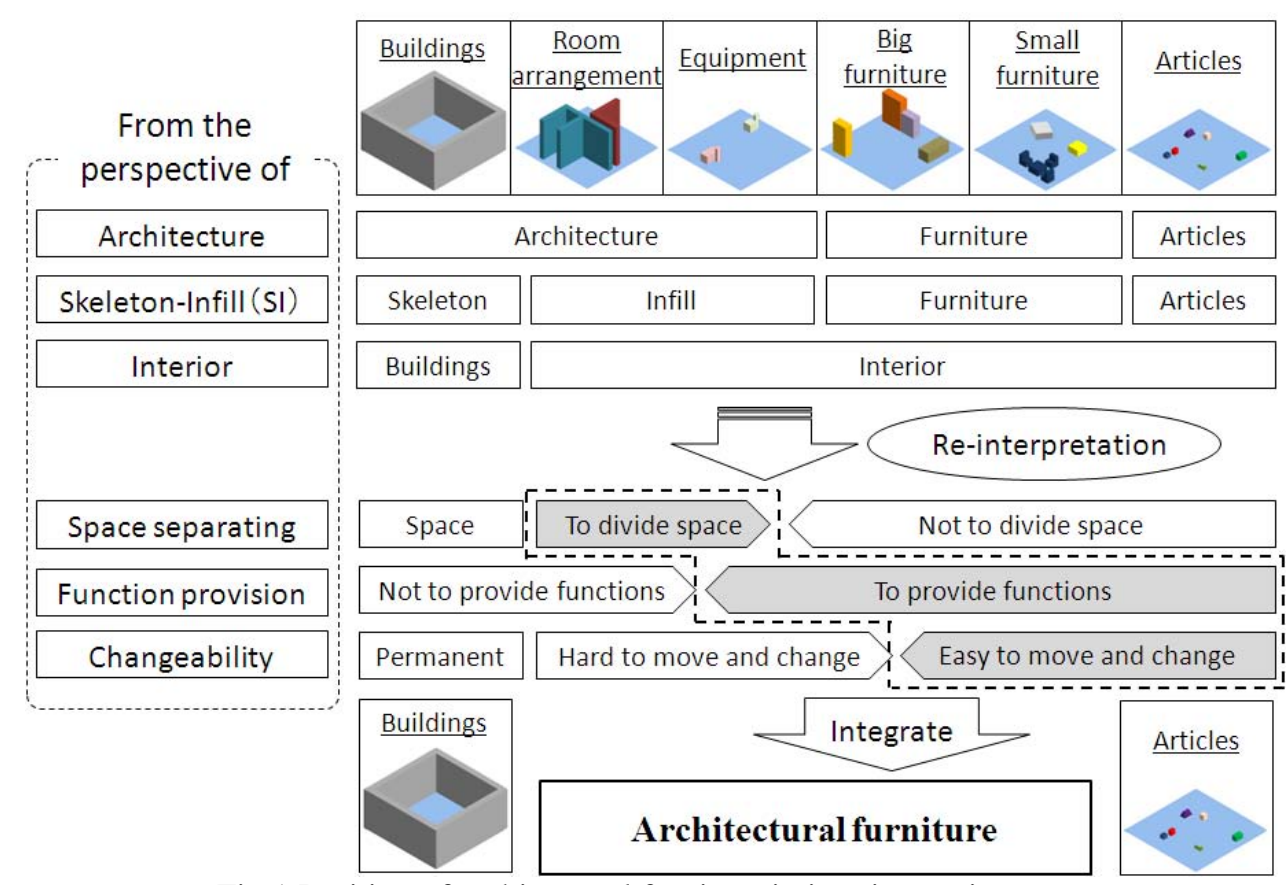

Fig.1 Position of architectural furniture in interior environment

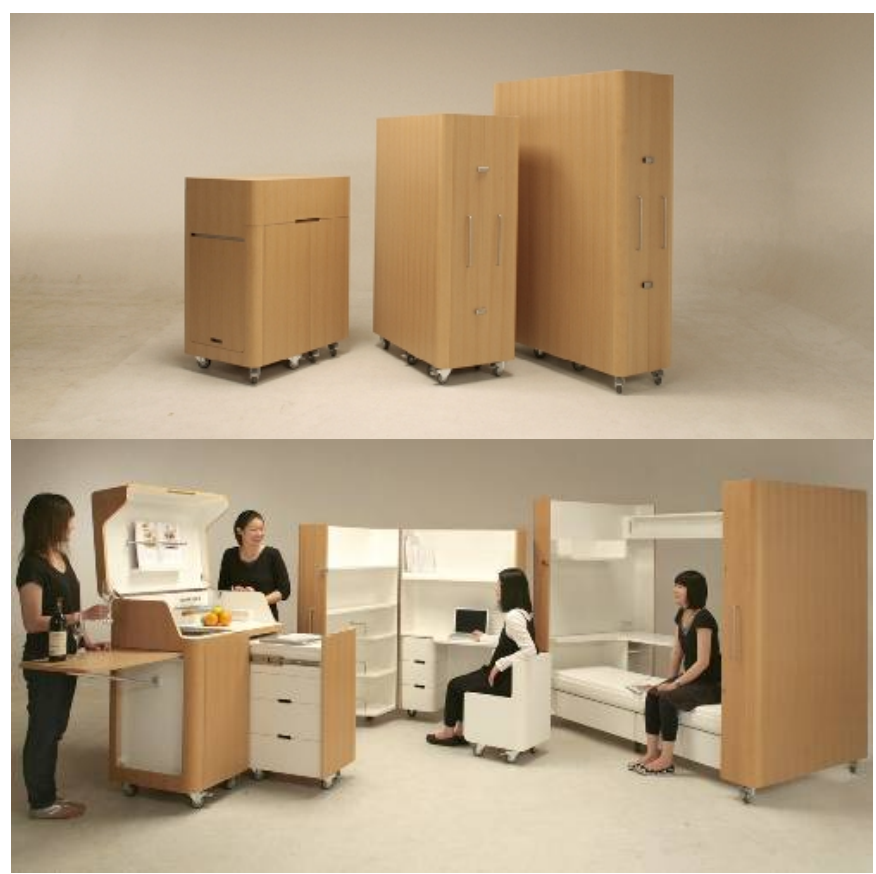

Fig.2 Folding in and out of three types of Architectural Furniture 
On the other hand, if the interior elements are reinterpreted from the perspectives of 3 natures of architectural furniture: space separating function, function provision, and changeability, room arrangement divides space and equipment, big and small furniture do not divide space in terms of space separating function; building and room arrangement do not provide functions with space and the other elements provide functions therewith in terms of function provision; and building is to be permanent, room arrangement and equipment are to be hard to move and change, and the other elements are easy to move and change in terms of changeability.

Fig.2 shows the examples of architectural furniture, mobile kitchen, foldaway guest room and foldaway office, designed by Suzuki. Each architectural furniture has casters to realize easy operation by humans. When those are folded in, its appearances look like suits case. When those are folded out, kitchen space, guest room, and study room appears. However, one or two operators are required due to the size and weight.

\subsection{Robotized structurization of living environment}

On the other hand, there are many researches which apply information and robot technology into living environment to give intelligence and achieve various services. For example, Sato developed robotic room which support daily activities of bedridden patients/student living alone in the room, using embedded sensors in furniture and robot arm [7]. Hashimoto proposed intelligent space and developed DIND (distributed intelligent network device) which had various sensors and communication device, and then studied the navigation of robots, wheelchair and people with visually impairment [8]. Ohara studied ubiquitous robot system which provides physical services by cooperation with distributed robot functions in environment [9]. Sugano developed WABOT-HOUSE. Robotic partition and movable kitchen were installed in the house to realize daily changes in a layout to meet various life styles of the residents. Automatic change of the layout and cooperative movement with mobile robot were achieved using sensors and RFID in the environment [10]. However, the research which focused on efficiency improvement of the space is rare.

\section{SMART VARIABLE SPACE}

Architectural furniture is suitable for the change in a layout that is more daily than skeleton-infill. Additionally, the character of architectural furniture is effective for the efficiency improvement of the space. The efficiency improvement of the space shows "Amount of the function for each single space".

The amount of the function that can be given to the space is limited usually. Therefore, a past house had divided from living, kitchen, study, and the bedroom, etc. according to the function. The resident was moving the room in past living conditions according to the usage. At

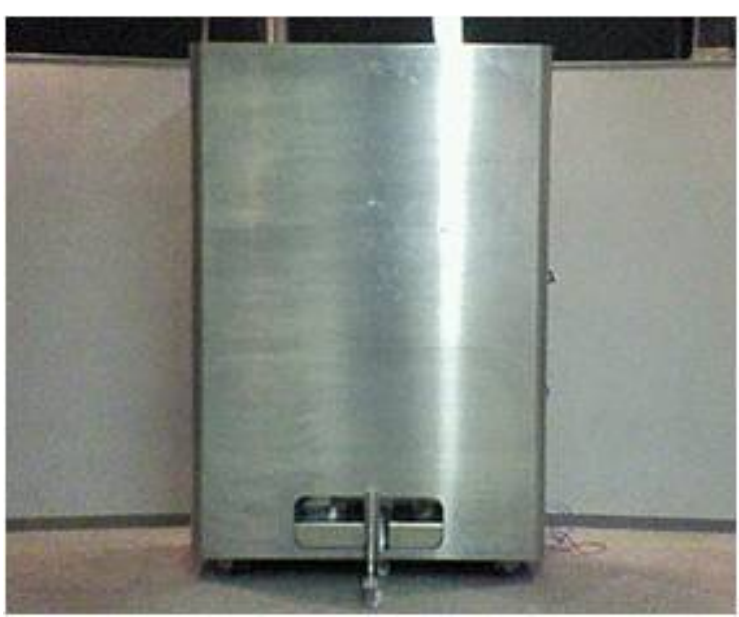

(a) Front view

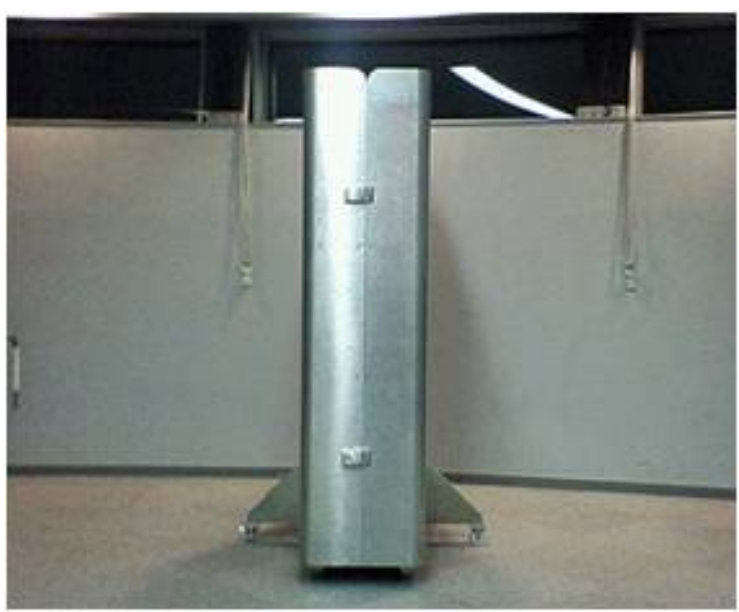

(b) Side view

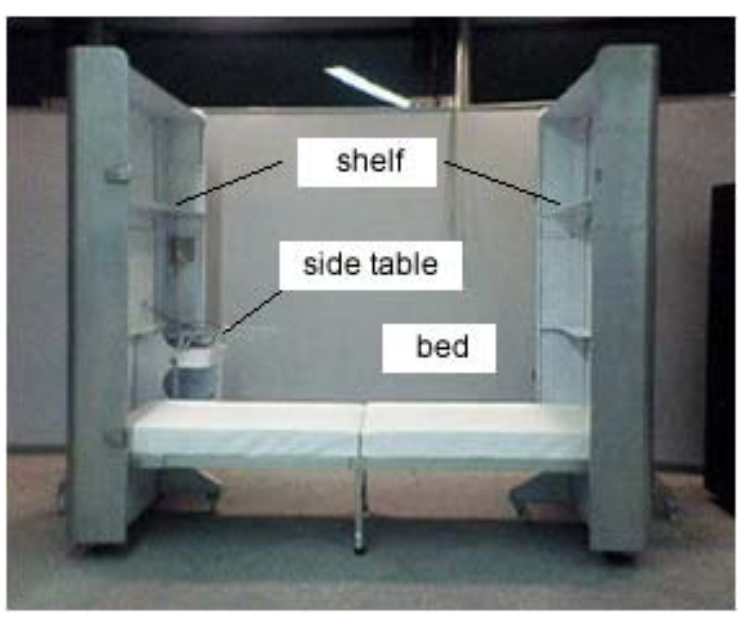

(c) Fold out

Fig.3 Appearances of bedroom module for smart variable space 
this time, it is thought that the room not used is a useless space in the viewpoint of the space efficiency improvement.

However, architectural furniture requires one or two operators due to the size and weight. Robot technology can solve the problem; even more can add some intelligence and autonomy. Smart variable space is the expanded concept of architectural furniture by combining with robot technology. The space is composed with robotic architectural furniture, such as bedroom, office room and kitchen, and can change its functions automatically according to the users demand or lifestyles. In this paper, we developed a bedroom module as the first step to realize the smart variable space.

\section{DEVELOPMENT OF BEDROOM MODULE}

\subsection{Specification}

Fig. 3 shows appearance of the bedroom module. The module pretends to a part of wall/partition when it is folded in, and the footprint is $0.53 \mathrm{~m}^{2}$. But the footprint is expanded to $2.45 \mathrm{~m}^{2}$ when it was folded out, and then bedroom which has a bed, shelves and side table appears. Table I shows the specification. To achieve automatic movement in limited area, four omnidirectional wheel units (Soai co. ltd.) are installed in the bottom. A brushless DC motor is also installed to support fold in/out movement. Two batteries (DC $12 \mathrm{~V}, 6 \mathrm{Ah}$ ) that are connected in a series are used as power source. Fig. 4 shows the system architecture. SH4 CPU board (General Robotix, Inc.) is used to control the ominidirectional wheel units and brushless DC motor according to the user commands which are send via host PC.

\subsection{Test operation}

In order to confirm the functions of developed bedroom module, we conducted test operation. The operator sent basic commands, go forward/backward, right/left turn, fold in/out according to the following operation procedure.

Table I. Specification of bedroom module

\begin{tabular}{|l|c|}
\hline \multirow{2}{*}{ Dimensions } & $\begin{array}{c}440[\mathrm{~W}] \times 1200[\mathrm{D}] \mathrm{x} 1770[\mathrm{H}] \mathrm{mm} \\
* 1\end{array}$ \\
\cline { 2 - 2 } Footprint & $\begin{array}{c}2040[\mathrm{~W}] \times 1200[\mathrm{D}] \mathrm{x} 1770[\mathrm{H}] \mathrm{mm} \\
* 2\end{array}$ \\
\cline { 2 - 2 } & $2.45 \mathrm{~m}^{2} * 1$ \\
\hline Weight & $200 \mathrm{~kg}$ \\
\hline Material & A5052, SUS304 \\
\hline Moving system & Omniwheel unit (50W, 24V) x 4 \\
\hline $\begin{array}{l}\text { Folded in/out } \\
\text { system }\end{array}$ & DC Motor (100W, 24V) x 1 \\
\hline Power source & Battery (DC 12V, 6Ah) x 2 \\
\hline
\end{tabular}

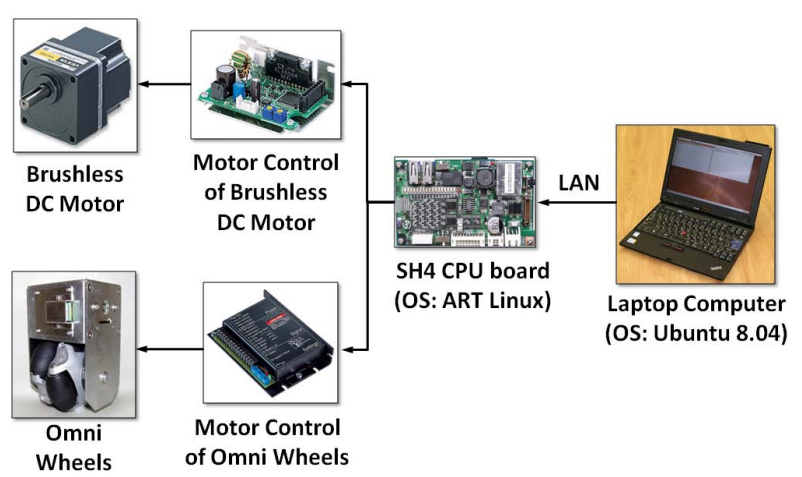

Fig.4 System architecture of bedroom module

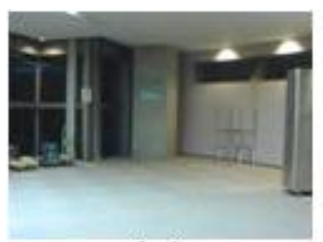

(a)

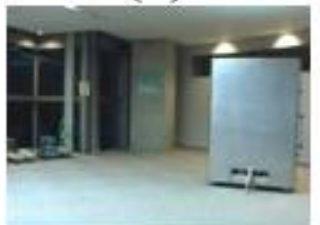

(b)

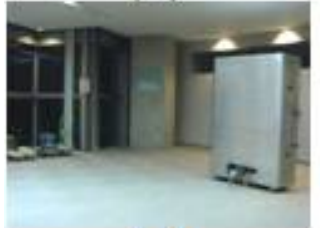

(c)

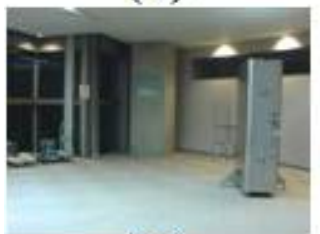

(d)

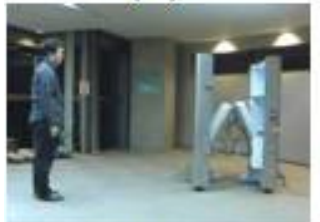

(e)

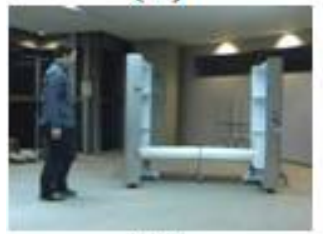

(f)

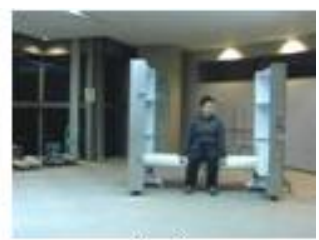

(g)

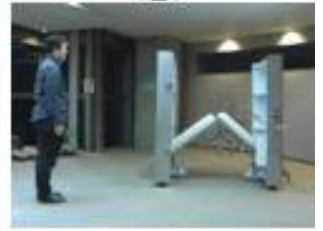

(h)

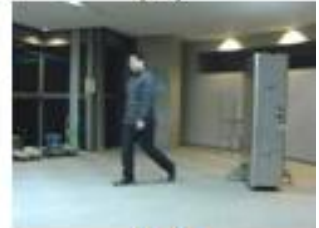

(i)

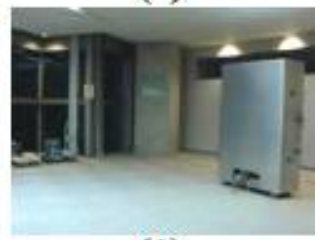

(j)

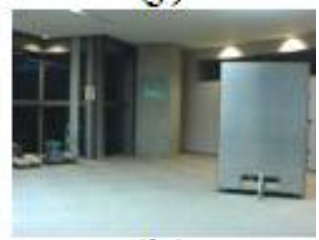

(k)

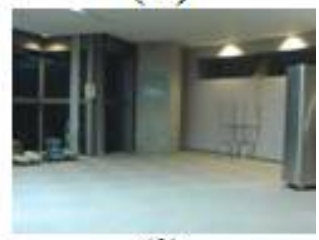

(1)
Fig.5 Result of test operation 
a). Go forward $1[\mathrm{~m}]$

b). Turn right by $90^{\circ}$

c). Fold out

d). Fold in

e). Turn left by $90^{\circ}$

f). Go back to start position

Fig.5 shows the results. The bedroom module could move and fold out/in according to the operation. Currently, fold out/in motion requires person who unlock/lock the fastener for prevention of module opening. However, required time for fold out/in was 20 seconds. On the other hand, architectural furniture, foldaway guestroom requires two persons and 1 minute to fold out/in it. We consider a merit of robotized architectural furniture was confirmed.

\section{CONCLUSION}

The new methods which improve space usage efficiency are required in cities. Architectural furniture, furniture combining architectural functions, was one of the methods. It provided space separating, function provision, and changeability of the space. However, its operation was depended on human power; therefore there were the limitation of changeability.

In this paper, we proposed smart variable space which improves space usage efficiency by changing its module automatically. The space was composed with various robotized architectural furniture modules, such as bedroom, office room and kitchen. The bedroom module was developed as an example of the module; and its basic movements were confirmed by test operation.

Autonomous movement using environment sensors, such as CCD, LRF, and RFID tags, will be presented in the next time. Further, we will develop other modules such as office room and kitchen in the future.

\section{REFERENCES}

[1] National Institute of Population and Social Security Research, Population Projections for Japan: 2001-2050, January, 2002.

[2] K. Kaido, "Urban Densities and Local Facility Accessibility in Principal Japanese Cities”, $5^{\text {th }}$ Symposium of international Urban Planning and the Environment Association (IUPEA), 2007

[3] http://www.studio-nasca.com/

[4] A. V. Vegesack, Mathias Schwartz-Clauss, Manfred Allie, and Barbara Haub, “ LIVING IN MOTION”, Vitra Design Stiftung, 2002

[5] T. Suzuki, "Architectural Furniture -furniture combining architectural functions”, AIDIA Journal, vol.7, 2007

[6] T. Suzuki and K. Honma, "Development and Validation of “Architectural Furniture” Research on Furniture Combining Architectural Functions ("Architectural Furniture")", AIDIA Journal, Vol.8, 2008

[7] T. MORI and Tomomasa SATO, "Human Support System:Robotic Room”, Systems, control and information, Vol. 44, No. 3, pp. 151-156, 2000

[8] J. H. Lee and H. Hashimoto, "Intelligent Space - Its concept and contents -", Advanced Robotics Journal, Vol. 16, No. 4, 2002.

[9] K. Ohara, K. Ohba, B. K. Kim, T. Tanikawa and S. Hirai, "Ubiquitous Robot with Ubiquitous Function Activate Module”, INSS 2005, Sandi ego, USA, 2005.

[10] http://www.wabot-house.waseda.ac.jp/

[11] http://www.soai-net.co.jp/service_03/omuni.html

[12] http://www.generalrobotix.com/ 